Revista Colombiana de Ciencia Animal RECIA ISSN: 2027-4297

reciaeditor@unisucre.edu

Universidad de Sucre

Revista Colombiana de Ciencia Animal Colombia

\title{
El saber pedagógico y los valores morales
}

\section{Pedagogical knowledge and moral values}

Montes-Vergara D, De La Ossa J. El saber pedagógico y los valores morales. Rev Colombiana Cienc Anim. Recia. 2019; 11(2):Articulo723. DOI: https://doi.org/10.24188/recia.v11.n2.2019.723

Universidad de Sucre, Colombia

Los autores permiten a RECIA reimprimir el material publicado en él. En caso de que un autor quiera traducir o usar una publicación parcial o completa de nuestro Diario, el autor debe obtener un permiso por escrito del editor de la revista.

Revista Colombiana de Ciencia Animal - RECIA está distribuido bajo una Licencia Creative Commons Atribución-CompartirIgual 4.0 Internacional. 


\title{
El saber pedagógico y los valores morales
}

\author{
Pedagogical knowledge and moral values
}

Jaime De La Ossa V. Ph.D.

DOI: https://doi.org/10.24188/recia.v11.n2.2019.723

Universidad de Sucre, Facultad de Ciencias Agropecuarias,

Sincelejo, Colombia.

delaossaeditor@unisucre.edu.co

(D) https://orcid.org/0000-0002-9374-7765

Donicer Montes-Vergara. Ph.D.

Universidad de Sucre, Facultad de Ciencias Agropecuarias,

Sincelejo, Colombia.

donicer.montes@unisucre.edu.co

Dhttps://orcid.org/0000-0002-2860-0505

El saber pedagógico es un fundamento del ejercicio académico, dentro del cual están implícitas las relaciones interdisplinarias y las transdisciplinarias (1), las que por su misma naturaleza deben ser abordadas permanentemente por el docente, tanto dentro del aula como en los trabajos independientes del estudiante, siendo este el modo en que fluye el ejercicio profesoral.

Pero qué se entiende por saber pedagógico, al respecto Foucault (2), indica que es todo aquello que se puede decir, que se puede nombrar, que se puede enunciar de un objeto en una práctica discursiva determinada; el dominio de los objetos que tienen - o no - pretensiones de cientificidad; el campo de correlación o de subordinación de los enunciados en los cuales los objetos aparecen, emergen, se transforman, forman dispersiones, traman una red de relaciones y regularidades que constituyen las condiciones de posibilidad de la emergencia de los discursos (1).

En este mismo sentido, es valioso tener presente lo que se puede entender por saber, según Zuluaga (3), se constituye en espacios de construcción social, emergentes de recortes de saberes disciplinares, de ciencias o de disciplinas que tengan alguna relación con la práctica discursiva de la que efectivamente algo se dice o se enuncia. Igualmente, constituye instancias de regulación, de marcación y demarcación de los discursos, de los sujetos y de los poderes, al modo que se constituyen en condición de posibilidad, también, para la estructuración de las relaciones de poder y de la configuración de sujetos; aquellos saberes son, a la vez, configurados y reconfigurados por dichos sujetos (1).

Surge entonces una pregunta que a todos preocupa: ¿Puede un docente con posibilidades discursivas limitadas ejercer efectivamente el papel de educador que la sociedad requiere? Las respuestas van desde la simplicidad de creer que por ser poseedor de un determinado título universitario - en cualquier nivel - ya le están dadas las calidades per se; peor aún, si se considera que la labor educativa es una opción de trabajo de última instancia; más grave todavía, si labora con los conocimientos específicos pero sin los fundamentos pedagógicos y humanísticos requeridos. La cuestión es seria y no debe tomarse a la ligera, no se debe olvidar que en las manos de los docentes está la formación de las nuevas generaciones y allí radica el buen desarrollo del país. 
Por ejemplo, los valores morales son fundamentales en la parte discursiva que ayuda a la formación del estudiante, son parte inherente de las relaciones interdisplinarias y las transdisciplinarias que le permitirán al alumno, de la mano del docente, alcanzar la integralidad. No podemos pretender tener ciudadanos muy capaces en un área específica, pero carentes de estos valores, porque tendrían dificultades de fondo para adoptar una actitud transformadora ante los retos de la sociedad y difícilmente podrían tener comportamientos responsables en distintas esferas de su vida (4).

Respecto de los valores cívicos, es importante tener presente como lo señalan Aranda et al (4), que estos se establecen en el proceso de adquisición y expresión de cualidades morales, las cuales se adquieren por modelos de convivencia y se manifiestan en la experiencia cotidiana del individuo. Así, sobre la base del conocimiento y la exigencia de las normas morales vigentes en la sociedad, se va estableciendo una relación de progresiva aceptación hacia ellas, de su incorporación a la conducta, de sentimientos de necesidad de estas formas de ser, de jerarquizarlas sobre otras, de su inclusión en aspectos internos de especial significación personal (4).

\section{Entonces:}

¿Qué sucedería si la comunidad educativa le apuesta a la tendencia de hacer o lograr algo con un mínimo esfuerzo, de manera fácil, y además lo ve como una solución efectiva?

¿Podrimos deducir que además de la crisis pedagógica nos enfrentamos a una crisis moral o que la crisis moral nos ha lleva a una crisis pedagógica?

\section{REFERENCIAS}

1. Sánchez-Amaya T, González-Melo HS. Saber pedagógico: fundamento del ejercicio docente. Educ Educ. 2016; 19(2):241-253. DOI: http://dx.doi.org/10.5294/edu.2016.19.2.4

2. Foucault M. La arqueología del saber. México: Siglo XXI; 2006. http://www.medicinayarte.com/

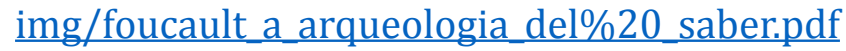

3. Zuluaga O. Pedagogía e historia. La historicidad de la pedagogía. La enseñanza, un objeto de saber. Colombia: Editorial Universidad de Antioquia; 1999. http://files.practicapedagogica.webnode. es/200000036-e3befe4b91/Pedagogia\%20e\%20historia\%20Zuluaga.pdf

4. Aranda CB, Paz DI, Ramos RG, Ávila SY, Durán RD. El proceso de formación de los jóvenes universitarios en la concepción de educación de género y valores cívicos. MEDISAN. 2017; 21(8):10271037. https://www.medigraphic.com/pdfs/medisan/mds-2017/mds178i.pdf 